\title{
A Review of Rare Associations of Horseshoe Kidney: Highlight of a Rare Clinical Case of Polycystic Horseshoe Kidney, Liver Cyst, and Uterine Prolapse
}

\author{
Authors: \\ *Ayun Cassell,', Mohamed Jalloh, ${ }^{1}$ Papa S. Diop,, ${ }^{2}$ Mouhamadou M. \\ Mbodji, ${ }^{1}$ Medina Ndoye, ${ }^{1}$ Abdourahmane Diallo, ${ }^{1}$ Saint Charles Kouka, ${ }^{3}$ \\ Issa Labou, ${ }^{1}$ Lamine Niang, ${ }^{1}$ Serigne M. Gueye ${ }^{1}$ \\ 1. Department of Urology and Andrology, Hôpital Général de Grand Yoff, Dakar, \\ Senegal \\ 2. Department of General Surgery and Surgical Specialities, de I'Université Cheikh \\ Anta Diop, Dakar, Senegal \\ 3. UFR Sante, Universite de Thies, Thies, Senegal \\ ${ }^{*}$ Correspondence to ayuncasselliii@gmail.com
}

Disclosure: $\quad$ The authors have declared no conflicts of interest

Acknowledgements: The authors would like to give special thanks to the departments of surgery and urology at Hôpital Général de Grand Yoff.

Received:

28.10 .19

Accepted:

O2.12.19

Keywords:

Horseshoe kidney, polycystic, uterine prolapse.

Citation:

EMJ Urol. 2020;8[1]:22-28.

\section{Abstract}

Horseshoe kidney is the most common renal fusion anomaly occurring in $0.15-0.25 \%$ of the general population. Horseshoe kidney is usually asymptomatic but may present with disease-like infections, urolithiasis, malignancy, polycystic disease, and other associated anomalies that may require intervention. Polycystic horseshoe kidney is rare, its association with uterine prolapse has not been reported in the literature, and it can only be postulated as an associated risk factor for uterine prolapse when found in the pelvis. The authors reviewed rare associations of horseshoe kidney and the management of these associated anomalies and disease conditions with the clinical vignette of a 60-year-old female with low-lying/lumbo-pelvic polycystic horseshoe kidney and hepatic cyst, and concomitant uterine prolapse requiring total abdominal hysterectomy at a Senegalese Hospital.

\section{INTRODUCTION}

Horseshoe kidney is the most common renal fusion anomaly occurring in $0.15-0.25 \%$ of the general population. ${ }^{1-3}$ The male to female ratio is $2: 1,{ }^{3}$ and although horseshoe kidney has been reported in identical twins and siblings, there is currently no established genetic link. ${ }^{4}$ Horseshoe kidney is also seen in individuals

with chromosomal anomalies and in $7 \%$ of those with Turner's syndrome. ${ }^{5}$ The incidence of horseshoe kidney exists in three age groups: ${ }^{4}$ in children, the pathology is diagnosed as part of a congenital anomaly; in young adults, it is diagnosed as a component of delayed puberty, for example in Turner's syndrome; and in adult patients, horseshoe kidney is diagnosed incidentally following a transabdominal 
ultrasound, intravenous urogram, or CT scan for detection of other diseases. ${ }^{4}$

In $90 \%$ of cases, fusion occurs along the lower pole moiety; however, in $5-10 \%$ of patients, fusion may occur along the upper pole giving the appearance of an inverted horseshoe kidney. ${ }^{4}$ The isthmus of the horseshoe is usually a fibrous band or parenchymatous renal tissue connecting the horseshoe kidney at lumbar vertebrae 2-4 (L2-L4). ${ }^{4}$ Horseshoe kidney is a developmental variance usually occurring between 4 to 6 weeks of intrauterine life. The fusion of the lower pole of the kidney during this period creates a U-shaped kidney that is prevented from ascending to its normal level at the fourth lumbar vertebra by the inferior mesenteric artery originating from the aorta at the third lumbar vertebra. ${ }^{4}$ Subsequently, the normal posterior rotation of the kidney is not possible, leaving the renal pelvis in an anterior plane.

Horseshoe kidney is usually asymptomatic but association with ureteropelvic junction obstruction, infection, and urolithiasis has been frequently reported, ${ }^{6}$ and other rare associations including polycystic horseshoe kidney, malignancies, and vascular anomalies have been reported. The incidence of renal pelvis cancer associated with horseshoe kidney has been estimated at $19.8 \%,{ }^{2}$ and renal cell carcinoma has accounted for approximately $50.0 \%$ of malignancies found in horseshoe kidney. ${ }^{3}$ The incidence of renal cell carcinoma is, however, the same in the population with nonfused kidney. ${ }^{3}$

Evidence has revealed that horseshoe kidney is associated with both venous and arterial anomalies. Based on results from several reports, there could be aberration of the renal artery to the horseshoe kidney along the following arterial vasculature: internal iliac artery (1.94\%), iliolumbar artery (2.90\%) and phrenic artery (0.97\%), common iliac artery (40.0\%), median sacral artery (2.90\%), external iliac artery (0.97\%), and the inferior mesentery artery (no data available). ${ }^{4}$ Venous anomalies associated with horseshoe kidney are ten times more common than those in the general population. Some variations include double inferior vena cava (IVC), left-sided IVC, and preisthmic IVC. ${ }^{4}$
Polycystic horseshoe kidney is a rare association with a prevalence of 1 in 134,000 to 1 in 8,000,000 cases; ${ }^{7}$ however, polycystic kidney disease and horseshoe kidney have separate aetiopathogeneses. Polycystic kidney disease itself is an autosomal dominant genetic disease and a major cause of renal failure. Studies have implicated two genes: PKD1, located on the short arm of chromosome 16 and accounting for $95 \%$ of cases; and PKD2, localised on chromosome 4, which accounts for $5 \%$ of cases. ${ }^{7}$

Polycystic horseshoe kidney plus liver cyst with associated uterine prolapse has not been reported in the literature. The exact incidence of uterine prolapse is unknown but accounts for $20 \%$ of women awaiting urogynaecological surgery in the UK. ${ }^{8}$ Multiparity, race, older age, family history, increased BMI, constipation, menopause, and increased intra-abdominal pressure have been reported as established risk factors for uterine prolapse. ${ }^{8}$ Nevertheless, there have been no published data on horseshoe kidney as a potential aetiologic factor. Horseshoe kidney, an anomaly itself, may not require any intervention except for the treatment of coexisting anomalies, disease, or complications. Frequent complications that may warrant intervention include ureteropelvic junction obstruction, suppurative infection, and obstructing urolithiasis. Other rare associations or complications that may need further management include malignancies, vascular anomalies, or polycystic disease.

This review emphasises rare associations of horseshoe kidney and management of associated anomalies with the clinical case of a 60-year-old female with low-lying/lumbopelvic polycystic horseshoe kidney with hepatic cyst and concomitant uterine prolapse requiring total abdominal hysterectomy at a Senegalese hospital.

\section{CLINICAL CASE}

A 60-year-old female (gravida 5 para 5; BMI $29 \mathrm{~kg} / \mathrm{m}^{2}$ ) presented to the obstetrics and gynaecology outpatient department with history of intermittent vaginal bulge for $>5$ years with associated dysuria that resolved with reduction of the bulge. The prolapse 
occurred while standing or working but reduced manually during bed rest. Her fourth pregnancy was complicated by prolonged and obstructed labour that necessitated assisted vaginal delivery. There was no family history of hypertension or renal disease ascertained.

Her physical exam revealed a Stage 4 pelvic organ prolapse approximately $8 \mathrm{~cm}$ beyond the vaginal introitus. The prolapsed uterus was pinkish with areas of hyperaemia but no sign of ulcerations. Estimation using the Pelvic Organ Prolapse Quantification (POPQ) was not documented. Further examination with a contrast CT scan showed an incidental finding of a hepatic cyst of $8.0 \times 7.5 \mathrm{~cm}$ in diameter in segment, fusion of the right and left kidney along the midline of vertebral bodies $L 4$, L5, and S1, with a $4 \times 4 \mathrm{~cm}$ cyst in the upper pole of the left kidney with multiple smaller cysts bilaterally.

Consultation with the urologists and general surgeons showed that she had a polycystic horseshoe kidney and a liver cyst that had been asymptomatic for years. The vital signs were all stable during the examination (blood pressure: 130/80 mmHg; pulse rate: 96 beats per minute; respiratory rate: 18 breaths per minute). Serum creatinine, blood urea nitrogen, complete blood count, coagulation profile, liver function test, and liver enzymes were normal. Her blood urea nitrogen was $15.00 \mathrm{mg} / \mathrm{dL}$, albumin was $4.00 \mathrm{~g} / \mathrm{dL}$, creatinine was $0.95 \mathrm{mg} / \mathrm{dL}$, and alanine transaminase was $30.00 \mathrm{U} / \mathrm{L}$, aspartate transaminase was $36.00 \mathrm{U} / \mathrm{L}$, and lactate dehydrogenase was $191.00 \mathrm{U} / \mathrm{L}$. Routine urine analysis showed proteinuria (1+) and haematuria $(1+)$ with a normal number of red blood cells in high power field.

With a multidisciplinary team, she underwent a total abdominal hysterectomy for a Stage 4 pelvic organ prolapse. Significant intraoperative findings revealed that the horseshoe kidney was abnormally lower in the pelvis and descended deeper during ventilation. It was assumed at the time that the repetitive descending of the horseshoe kidney may have previously contributed to the uterine prolapse. Her postoperative recovery was unremarkable. Follow-up laboratory tests have since shown a normal renal function and liver function.

\section{METHODOLOGY}

This review of horseshoe kidney with a literature search conducted from 2000 to 2019 used the search engines Google, Google Scholar, African Journal Online, and PubMed. The English-language literature was explored using the search term "horseshoe kidney", and appended associations ("polycystic horseshoe kidney", "polycystic horseshoe kidney + uterine prolapse", "horseshoe kidney + pyelonephritis", "horseshoe kidney + malignancy"). A total of 23 publications, two review articles, and 21 case reports of rare associations of horseshoe kidney were retrieved and included in the study. Other usual or frequent associations of horseshoe kidney such as horseshoe kidney plus uteropelvic junction obstruction, and horseshoe kidney plus urolithiasis, were excluded from the study. A total of 21 case reports of horseshoe kidney (20 published reports and one clinical vignette) were selected and reviewed for the study including polycystic horseshoe kidney, horseshoe kidney plus pyelonephritis, and horseshoe kidney plus malignancy. A total of 21 publications and case reports were reviewed for age, gender, associations, diagnostic modalities, and treatment. The data is represented in Tables 1 and 2 and a qualitative analysis is reported in the main text of the results. The clinical vignette of a 60-year-old female with polycystic horseshoe kidney associated with liver cyst and vaginal prolapse requiring total abdominal hysterectomy at a Senegalese hospital was highlighted specifically in the review as shown in Figures 1A-F.

\section{RESULTS AND DISCUSSION}

\section{Horseshoe Kidney and Associated Infections}

A total of 21 case reports of horseshoe kidney (20 published reports and one clinical vignette) were reviewed. The age of diagnosis ranged from 22.0 years to 83.0 years, with an average of 53.4 years. There were three reports of horseshoe kidney with associated infections: xanthogranulomatous pyelonephritis and renal calculi, ${ }^{9}$ emphysematous pyelonephritis and ureteric stones, ${ }^{10}$ and pyonephrosis and xanthogranulomatous pyelonephritis. ${ }^{6}$ 
Table 1: Age, sex, horseshoe kidney with associated ureteropelvic junction obstruction, vascular anomalies, infection, or polycystic kidney disease, and imaging modalities and treatment options.

\begin{tabular}{|c|c|c|c|c|c|}
\hline Study & Age (years) & Sex & $\begin{array}{l}\text { Horseshoe kidney and } \\
\text { associations }\end{array}$ & $\begin{array}{l}\text { Diagnostic } \\
\text { modalities }\end{array}$ & Treatment \\
\hline Tsuru et al. ${ }^{1} 2016$ & 53 & M & $\begin{array}{l}\text { UPJO and left duplex } \\
\text { collecting system }\end{array}$ & $\begin{array}{l}\text { Three-dimensional } \\
\text { CT scan, } \\
\text { ureteroscopy and } \\
\text { cystoscopy }\end{array}$ & $\begin{array}{l}\text { Laparoscopic } \\
\text { pyeloplasty }\end{array}$ \\
\hline Basson et al. ${ }^{9} 2013$ & $\geq 18$ & N/A & Right XP and renal calculi & CT scan & N/A \\
\hline Gargouri et al..$^{10} 2014$ & 67 & $\mathrm{~F}$ & $\begin{array}{l}\text { Left emphysematous } \\
\text { pyelonephritis and left pelvic } \\
\text { ureteric stone }\end{array}$ & $\begin{array}{l}\text { CT scan and } \\
\text { 99m-Tc-DMSA }\end{array}$ & $\begin{array}{l}\text { Antibiotics, PCD, and } \\
\text { ureterolithotripsy }\end{array}$ \\
\hline $\begin{array}{l}\text { Fernandez et al. }{ }^{6} \\
2018\end{array}$ & 64 & $\mathrm{~F}$ & $\begin{array}{l}\text { Left staghorn calculi, } \\
\text { massive pyonephrosis, and } \\
\text { XP }\end{array}$ & $\begin{array}{l}\text { CT scan and renal } \\
\text { scintigram }\end{array}$ & $\begin{array}{l}\text { Antibiotics, PCD, } \\
\text { and left laparoscopic } \\
\text { heminephrectomy }\end{array}$ \\
\hline Özsin et al. ${ }^{11} 2018$ & 65 & $M$ & Aortoiliac occlusive disease & $\begin{array}{l}\text { Intraoperative, } \\
\text { multislice CT scan, } \\
\text { and CT angiogram }\end{array}$ & Aortobifemoral bypass \\
\hline Guvendi et al. ${ }^{12} 2016$ & 41 & $\mathrm{~F}$ & Left renal vein compression & $\begin{array}{l}\text { CT scan and } \mathrm{CT} \\
\text { angiogram }\end{array}$ & N/A \\
\hline $\begin{array}{l}\text { Batista Peres et al. }{ }^{13} \\
2006\end{array}$ & 36 & $\mathrm{~F}$ & $\begin{array}{l}\text { Polycystic HSK and } \\
\text { liver cyst }\end{array}$ & $\begin{array}{l}\text { Ultrasound and } \\
\text { CT scan }\end{array}$ & N/A \\
\hline $\begin{array}{l}\text { Shahreyar et al. } \\
2005\end{array}$ & 47 & $\mathrm{~F}$ & Bilateral polycystic HSK & Ultrasound & $\begin{array}{l}\text { Bilateral nephrectomy } \\
\text { and transplantation }\end{array}$ \\
\hline Jehangir et al. ${ }^{14} 2006$ & 22 & $\mathrm{~F}$ & $\begin{array}{l}\text { Bilateral polycystic HSK and } \\
\text { renal calculi }\end{array}$ & $\begin{array}{l}\text { Ultrasound and } \\
\text { CT scan }\end{array}$ & N/A \\
\hline Ram et al..$^{15} 2013$ & 32 & M & $\begin{array}{l}\text { Polycystic HSK and } \\
\text { liver cyst }\end{array}$ & $\begin{array}{l}\text { Ultrasound and } \\
\text { CT scan }\end{array}$ & N/A \\
\hline Ghonge et al. ${ }^{16} 2014$ & 45 & M & $\begin{array}{l}\text { Polycystic HSK and } \\
\text { liver cyst }\end{array}$ & CT scan & N/A \\
\hline Yildiz et al. ${ }^{17} 2019$ & 54 & $\mathrm{~F}$ & $\begin{array}{l}\text { Polycystic HSK and multiple } \\
\text { liver cysts }\end{array}$ & $\begin{array}{l}\text { Ultrasound and } \\
\text { CT scan }\end{array}$ & N/A \\
\hline Present study & 60 & $\mathrm{~F}$ & $\begin{array}{l}\text { Polycystic HSK and liver cyst } \\
\text { and uterine prolapse }\end{array}$ & CT scan & TAH \\
\hline
\end{tabular}

DMSA: dimercapto succinic acid; F: female; HSK: horseshoe kidney; M: male; N/A: not available; PCD: percutaneous drainage; TAH: total abdominal hysterectomy; UPJO: ureteropelvic junction obstruction; XP: xanthogranulomatous pyelonephritis.

The latter two cases of horseshoe kidney and pyelonephritis were managed with antibiotics, percutaneous drainage, and ureterolithotripsy, ${ }^{10}$ and antibiotics, percutaneous drainage, and laparoscopic heminephrectomy, respectively. ${ }^{6}$

Emphysematous pyelonephritis is a severe acute necrotising fasciitis of the renal parenchyma. The most common risk factor is diabetes (for $80 \%$ of cases) followed by obstruction from urolithiasis. ${ }^{10}$ Escherichia coli is the most common isolated organism followed by Klebsiella species. The diagnosis is confirmed by CT scan. ${ }^{10}$ Fulminant cases require a nephrectomy, admission to an intensive care unit, and antibiotics. Xanthogranulomatous pyelonephritis is an unusual form of chronic pyelonephritis which results from granulomatous destruction of the renal parenchyma and abscess formation, occurring in $1 \%$ of pineal parenchymal infections. ${ }^{9}$ 
Table 2: Age, sex, horseshoe kidney with existing malignancies, diagnostic modalities, and treatment options.

\begin{tabular}{|c|c|c|c|c|c|}
\hline Study & Age (years) & Sex & $\begin{array}{l}\text { Horseshoe kidney and } \\
\text { malignancy }\end{array}$ & $\begin{array}{l}\text { Diagnostic } \\
\text { modalities }\end{array}$ & Treatment \\
\hline Ito et al. ${ }^{2} 2018$ & 75 & $M$ & $\begin{array}{l}\text { Urothelial Ca of left renal } \\
\text { pelvis }\end{array}$ & CT-guided biopsy & $\begin{array}{l}\text { Chemotherapy and left } \\
\text { hemiureteronephrectomy }\end{array}$ \\
\hline Suzuki et al. ${ }^{18} 2018$ & 78 & $M$ & $\begin{array}{l}\text { Urothelial Ca of right } \\
\text { renal pelvis }\end{array}$ & CT scan and MRI & $\begin{array}{l}\text { Robotic RNU and } \\
\text { Isthmusectomy }\end{array}$ \\
\hline $\begin{array}{l}\text { Natsuyama et al. }{ }^{5} \\
2019\end{array}$ & 62 & M & $\begin{array}{l}\text { Urothelial Ca of left } \\
\text { distal ureter and } \\
\text { aberrant } \\
\text { renal artery }\end{array}$ & $\begin{array}{l}\text { CT scan and } \\
\text { indocyanine green } \\
\text { near-infrared } \\
\text { fluorescence }\end{array}$ & $\begin{array}{l}\text { Laparoscopic left } \\
\text { nephroureterectomy and } \\
\text { bladder resection }\end{array}$ \\
\hline Ohtake et al..$^{19} 2018$ & 83 & $\mathrm{~F}$ & Left RCC & CT scan & Laparoscopic PN \\
\hline $\begin{array}{l}\text { Yamamichi et al. } .^{20} \\
2019\end{array}$ & 63 & $M$ & Left clear cell RCC & 3D CT scan & Robot-assisted PN \\
\hline $\begin{array}{l}\text { Scavuzzo et al. }{ }^{21} \\
2017\end{array}$ & 37 & $\mathrm{~F}$ & $\begin{array}{l}\text { Right clear cell RCC and } \\
\text { pregnancy }\end{array}$ & Ultrasound and MRI & Radical nephrectomy \\
\hline $\begin{array}{l}\text { Nikoleishvili et al. }{ }^{3} \\
2017\end{array}$ & 69 & $M$ & Left clear cell RCC & $\begin{array}{l}\text { Ultrasound and } \mathrm{CT} \\
\text { scan }\end{array}$ & Laparoscopic PN \\
\hline Tijani et al. ${ }^{22} 2017$ & 69 & $\mathrm{~F}$ & $\begin{array}{l}\text { Left clear cell Ca and } \\
\text { aberrant renal artery }\end{array}$ & CT scan & $\begin{array}{l}\text { Open radical } \\
\text { nephrectomy and } \\
\text { isthmusectomy }\end{array}$ \\
\hline
\end{tabular}

Ca: carcinoma; F: female; M: male; PN: partial nephrectomy; RCC: renal cell carcinoma; RNU: radical nephroureterectomy.

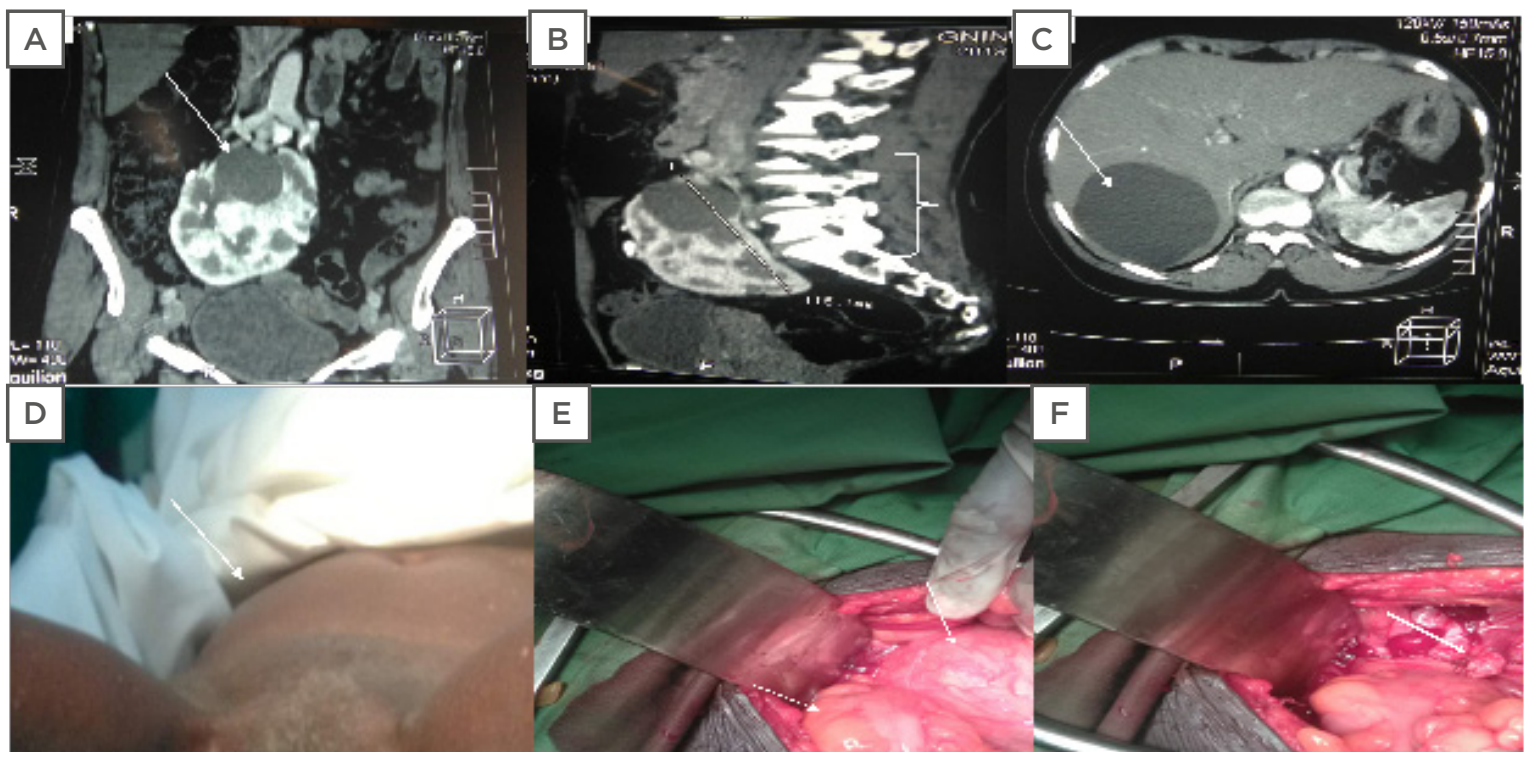

Figure 1: CT scan and clinical and intraoperative evidence of polycystic horseshoe kidney.

A) A $4 \times 4 \mathrm{~cm}$ renal cyst in the left upper pole moiety of the horse kidney with multiple smaller cysts. B) The polycystic horseshoe kidney at the L2-S1 vertebrae. C) An $8.0 \times 7.5 \mathrm{~cm}$ simple cyst in Segment VII of the liver. D) A uterine prolapse. E) The left arrow shows the sigmoid colon and the right arrow reveals the intraoperative picture of the horseshoe kidney descending into the pelvis during ventilation. F) The white arrow shows the empty space in the pelvis after ascent of the horseshoe kidney. 
They are more common in females and result from infected obstructing urolithiasis. Features of lipid-laden and foamy macrophages are pathognomonic microscopic characteristics. ${ }^{9}$ CT scans may reveal a nonfunctioning kidney, obstructing renal calculus, contracted renal pelvis, and inflammatory changes in the perinephric fat.

\section{Horseshoe Kidney and Associated Vascular Anomalies}

Özsin et al. ${ }^{11}$ and Guvendi et al. ${ }^{12}$ reported horseshoe kidney with concurrent aortoiliac occlusive disease and left renal vein compression, diagnosed with multislice CT and CT angiography, respectively. Tsuru et al. ${ }^{1}$ also reported a rare case of horseshoe kidney with ureteropelvic junction and duplicated collecting system in a patient who underwent a laparoscopic pyeloplasty. Reports from published literature have shown that abdominal aortic aneurysm is frequently associated with horseshoe kidney; the true incidence of concurrent aortoiliac occlusive disease remains unknown, however. Many variations in the renal collecting system as well as renal vasculature, with the presence of varying renal accessory vessels occurring with a horseshoe kidney, have been reported. ${ }^{11}$ Ordones et al. ${ }^{23}$ reported that these vascular aberrations and duplications could be useful in rare cases of horseshoe kidney transplant. Multislice CT and CT angiography have been helpful in delineating the horseshoe kidney and their associated vasculature. Intervention in these patients without proper insight of the renal vasculature could lead to renal parenchymal necrosis, or major haemorrhage.

\section{Horseshoe Kidney and Associated Malignancies}

Reports of horseshoe kidney were associated with three cases of urothelial carcinoma; 2,5,18 two affecting the renal pelvis, and one involving the distal ureter associated with an aberrant renal artery. There were five reports of horseshoe kidney with renal cell carcinoma,,,19-21 predominantly clear cell variants. ${ }^{3,21,22}$ CT was mostly used for diagnosis. Treatment options were generally laparoscopic or robotic. Partial nephrectomy, 3,19,20 radical nephrectomy, ${ }^{21,22}$ hemi-nephroureterectomy, ${ }^{2}$ and radical nephroureterectomy with bladder resection ${ }^{5,18}$ were all management options. The treatments were based on staging and oncological principle of the various histologies. The incidence of tumours arising from renal fusion anomalies is approximately 5-13\%; however, $50 \%$ of these tumours are proven to be renal cell carcinomas. Although the risk of nephroblastoma and urothelial cancer seem to be higher in renal fusion anomalies, the incidence of renal cell carcinoma appears to be similar to the general population. ${ }^{3}$ Preoperative imaging of the blood vessel with $\mathrm{CT}$ angiogram is essential to avoid perioperative complications. The surgical options are open, laparoscopic, or robotic partial/radical nephrectomy based on the oncological principle, institutional capacity, and surgeon's expertise.

\section{Polycystic Horseshoe Kidney, Associations and Clinical Case}

There were seven cases of polycystic horseshoe kidney, ${ }^{8,13-17}$ including the case highlighted in Figures 1A-F. Five of the seven cases of polycystic horseshoe kidney were associated with single or multiple liver cysts. ${ }^{13,15-17}$ Shahreyar et al. ${ }^{7}$ reported on a case of polycystic horseshoe kidney with renal insufficiency that necessitated bilateral nephrectomy and renal transplantation; the outcome of the intervention was not elucidated in the report. Polycystic horseshoe kidney is the combination of two different renal anomalies: horseshoe kidney is a fusion disorder during embryogenesis while polycystic disease of the kidney is a genetic disease of autosomal dominant inheritance. Adult polycystic kidney disease is the third most common aetiology of end-stage renal failure. ${ }^{16}$ Remarkably, the patient in the current study maintained a normal renal function both before and after surgery as well as subsequent follow-up.

The case of polycystic horseshoe kidney reported in this review was associated with a liver cyst as well as a uterine prolapse requiring a total abdominal hysterectomy. The horseshoe kidney as reported in the clinical vignette was discovered incidentally by CT, similarly to other cases of renal fusion anomalies reported in adults (usually asymptomatic). The horseshoe kidney shown in Figures $1 \mathrm{~A}-\mathrm{F}$ was at a much lower level of vertebral segment (L4-S1), as shown on contrast enhanced CT scan. The 
usual position of a horseshoe kidney is in the hypogastrium at the second to fourth lumbar vertebrae. After its ascent, it is arrested by the inferior mesenteric artery at the third lumbar vertebra during the $7-9^{\text {th }}$ week of gestation. Moreover, it was observed to have protruded deeper into the pelvis intraoperatively during ventilation. This association has never been reported to the authors' knowledge, and neither has a pelvic kidney been reported as a risk factor for pelvic organ prolapse in females.

There is a strong probability that the polycystic horseshoe kidney and the uterine prolapse could have been separate pathologies. The patient in the clinical vignette presented with many established risk factors including older age, multiparity, complicated assisted vaginal delivery from prolonged and obstructed labour, menopause, and increased BMI. However, the depth of the horseshoe kidney in the pelvis during ventilation intraoperatively could not have been easily discarded as a concurrent aetiological factor. Because increased intraabdominal pressure has been identified as a causative agent, ${ }^{4}$ it is difficult to assume that continuous abutting of the horseshoe kidney against the uterus during respiration could have contributed to the prolapse of the uterus through the introitus.

\section{CONCLUSION}

Horseshoe kidney is the most common renal fusion anomaly. It is usually asymptomatic but may present with associated anomalies or disease-like infections, urolithiasis, malignancy, polycystic disease, and other associations requiring intervention. Polycystic horseshoe kidney is rare. It is a common cause of end-stage renal failure, but the patient in the clinical vignette maintained a normal renal function. Moreover, the association of polycystic horseshoe kidney, liver cyst, and uterine prolapse has never been reported. Currently, the evidence is insufficient to reach a conclusion, and there is difficulty in assuming that continuous abutting of the horseshoe kidney against the uterus during ventilation could have contributed to the prolapse of the uterus through the introitus.

\section{References}

1. Tsuru $\mathrm{N}$ et al. Laparoscopic pyeloplasty for ureteropelvic junction obstruction in an incompletely duplicated collecting system in a patient with a horseshoe kidney. Urology case reports. 2016;9:55-7.

2. Ito A et al. Renal pelvic cancer with spleen invasion arising in horseshoe kidney; a case report. Urol Case Rep. 2018;16:123-5.

3. Nikoleishvili D, Koberidze G. Retroperitoneoscopic partial nephrectomy for a horseshoe kidney tumour. Urol Case Rep. 2017;13:31-3.

4. Balawender $\mathrm{K}$ et al. Anatomical and clinical aspects of horseshoe kidney: a review of the current literature. Int $\mathrm{J}$ Morphol. 2019;37(1):12-6.

5. Natsuyama T et al. Indocyanine green near-infrared fluorescence imaging-guided laparoscopic heminephrectomy for left ureteral cancer in patient with horseshoe kidney. Case Rep Urol. 2019;2019:4859301.

6. Fernandez A et al. Laparoscopic heminephrectomy of chronically obstructed horseshoe kidney moiety with staghorn calculus, massive pyonephrosis, and xanthogranulomatous pyelonephritis. J Endourol Case Rep. 2018;4(1):39-41.

7. Shahreyar $\mathrm{M}$ et al. Polycystic horseshoe kidney. Indian J Nephrol.
2005;15:250-1.

8. Doshani A et al. Uterine prolapse. BMJ. 2007;335(7624):819-23.

9. Basson C, De Witt J.

Xanthogranulomatous pyelonephritis in a horseshoe kidney. SA J Radiol. 2013;17(1).

10. Gargouri MM et al. Conservative management of emphysematous pyelonephritis in a horseshoe kidney. Afr J Urol 2014;20(2):88-90.

11. Özsin KK. Intraoperative surprise in a patient with aorto-iliac occlusive disease: horseshoe kidney. Malawi Med J. 2018;30(4):296-7.

12. Guvendi B, Ogul H. Left renal vein compression and horseshoe kidney: an extraordinary association. Med Princ Pract. 2016;25(5):494-6.

13. Batista Peres LA et al. Polycystic horseshoe kidney. Nephrol Dia Transplant. 2006;22(2):652-3.

14. Jehangir B et al. Autosomal dominant polycystic kidney disease and nephrolithiasis in a horseshoe kidney a case report. JK-Practitioner. 2006;13(2):98-9.

15. Ram R et al. Polycystic horseshoe kidney. Clin Kidney J. 2013;6(1):103-4.

16. Ghonge N, Jasuja S. Polycystic horseshoe kidney: dealing with double trouble. Clin Kidney J.
$2014 ; 7(4): 413$.

17. Yildiz $\mathrm{G}$ et al. Polycystic horseshoe kidney and polycystic liver disease. World J Surg Surgical Res. 2019;2:1115.

18. Suzuki H et al. A case of renal pelvic cancer complicated by horseshoe kidney treated with robosurgeon gasless singleport retroperitoneoscopic nephroureterectomy. Case Rep Urol. 2018;20(18):1-4.

19. Ohtake $\mathrm{S}$ et al. Renal cell carcinoma in a horseshoe kidney treated with laparoscopic partial nephrectomy. Case Rep Oncol Med. 2018;2018:7135180.

20. Yamamichi G et al. Renal cell carcinoma in a horseshoe kidney treated with robot-assisted partial nephrectomy. Urol Case Rep. 2019;25:100902.

21. Scavuzzo A et al. Renal cell carcinoma in a pregnant woman with horseshoe kidney. Urol Case Rep. 2017;13:58-60.

22. Tijani $\mathrm{KH}$ et al. Renal cell carcinoma in a horseshoe kidney: report of a rare disease. Niger Postgrad Med J. 2016;23(4):232-4.

23. Ordones FV et al. Transplanting a horseshoe kidney: a case report and review of surgical strategies. Urol Case Rep 2018;21:119-21. 